\title{
Mark Blaug's unrealistic crusade for realistic economics
}

\author{
USKALI MÄKI \\ University of Helsinki
}

\begin{abstract}
Mark Blaug's normative methodology of economics is an attempt to articulate certain intuitions about how economic science could be improved by making it more "realistic". I discuss two such articulations, one in terms of falsificationist principles, the other in terms of an alleged trade-off between relevance and mathematical rigour. My conclusion is that Blaug's methodology is itself unrealistic, both descriptively and normatively. His (well intended) methodological prescriptions for the improvement of economics are not based on a systematic, consistent, descriptively adequate, and normatively viable account. I suggest that Blaug's intuitions can be developed into a more realistic account by incorporating the analysis of two further topics: economic modelling and the institutions of academic research.
\end{abstract}

Keywords: economic methodology, falsificationism, realism, realisticness, relevance, rigour, economic modelling, institutions of inquiry, Mark Blaug

JEL Classification: A11, A14, B31, B41

I first met Mark Blaug in May 1984 in Pittsburgh at the History of Economics Society (HES) meetings. I had read his Economic theory in retrospect (1978 [1962]) and The methodology of economics (1980), as well as many other of his smaller works. I had admired his mammoth knowledgeability as a historian. His fast reading skills and his capacity to store information were exceptional, and this showed in his confident interventions in conference sessions. Obviously, he knew that he knew. He was a superman as a producer and reproducer of historical information.

While my admiration for Mark as a historian was strong (even though not being a proper historian myself, I could not really judge), I was far less impressed by his methodological work. He must have sensed this. In the early 1990s, I was in London for a workshop, and

AUTHOR's NoTE: The writing of this paper has been supported by the Academy of Finland. Many thanks go to Luis Mireles-Flores for very helpful comments. 
Mark invited me for lunch in a pizzeria next to the British Library. After some frank and friendly conversations, he suddenly asked, "Why don't you ever cite my work?" Years later, after the second edition of The methodology of economics (1992 [1980]) had appeared, he gave me a copy with his hand-written inscription (dated 21-08-1997): "Since this is a book which you have never seen, I thought that you might like a copy-bedtime reading!"

The presupposition of Mark's question-i.e., that I never cite himwas not quite true. In 1990, I had published a paper on economic explanation in which I stated that very little had been written on the topic before, and added a footnote commenting that the subtitle of his 1980 book-"how economists explain"-was misleading as there was nothing about this topic in the book. The book was on the epistemology of theory assessment, and not on the practice of explanation in economics.

Our academic and personal relations were respectful and increasingly warm. For a decade, we collaborated (together with Roger Backhouse and Kevin Hoover) as the editorial team of the Journal of Economic Methodology. In 1997, I invited Mark to be one of the speakers at the conference on "Fact or fiction? Perspectives on realism and economics" organized on the occasion of my inauguration at Erasmus University Rotterdam. An extended version of his article "Ugly currents in modern economics" (Blaug 1997) was then included in the volume Fact and fiction in economics (Blaug 2002). ${ }^{1}$ Some years later, Mark joined us in Rotterdam as a visiting professor, to teach history of economics to the students in our programme at EIPE (Erasmus Institute for Philosophy and Economics). He also regularly attended the weekly EIPE research seminar that I coordinated, greatly enriching its lively discussions. We visited each others' homes (theirs in Leiden, ours in Rotterdam) and had wonderful conversations.

Yet, it remained true that I did not cite him frequently. That this bothered him was fairly understandable. Mark was after a better economic science that would be more realistic, one that would be more relevant to real-world concerns. But so was I! It was obvious that we

\footnotetext{
${ }^{1}$ Some years before, in the early 1990s, I had invited Mark to contribute to one of the methodology workshops I organized for the Finnish Doctoral Programme in Economics. In the course of those years, several other activists in the field had joined the workshops, including Bert Hamminga, Maarten Janssen, Dan Hausman, Tony Lawson, Jochen Runde, and Roger Backhouse. Mark's response to the invitation, a real letter written with his beautiful handwriting in real ink, was that he would be too expensive to us. I was amused. This was his humour.
} 
shared many broad intuitions about economics and good science. Why then did I not use his work more often? Now that I think of it, the reason probably was that he did not have a systematic and elaborate methodological theory that I could have considered an appropriately "realistic" theory about economics, both descriptively and normatively. In the following brief remarks, I will start explaining and justifying this answer, mainly focusing on Mark's ideas about falsifiability and relevance. I will then outline two themes that I believe are of central importance for elaborating the intuitions that Mark and I shared, namely: economic modelling and the institutions of economic inquiry.

\section{ELEMENTS IN BLAUG'S CAMPAIGN: FALSIFIABILITY AND RELEVANCE}

Caricaturing a little, Mark Blaug was a historian of economics who turned into a methodological preacher. His dissatisfactions with much of economics primarily were-or at any rate manifested themselves as-complaints about the procedures and principles that he believed guided economic inquiry. The outcome was bad science, he thought, because the theories economists regularly produce and use tend to be empirically unfalsifiable and-or-practically irrelevant. Blaug appealed to methodology as part of a project of helping economics perform better as a science. Indeed, his use of methodology was predominantly normative. The descriptive component in his normative campaign has mainly consisted of pointing out failures to conform to the principles of good science. It is perhaps somewhat paradoxical that a historian of economics would take on the role of a preacher in his methodological work, (mostly) prescribing rather than (mostly) describing the disciplinary activities of his subject.

Blaug ran a methodological campaign for a more realistic economics, but he did not consistently rely on a realistic methodological theory, or on realistic methodological arguments. 'Realisticness' and 'unrealisticness' are (themselves manifold) properties that can be ascribed both to economic theories and to their meta-theories. Blaug's meta-theoretical claims about economics often were descriptively unrealistic in that they tended to oversimplify and exaggerate, thereby ignoring important facts about scientific inquiry. This fortified the

\footnotetext{
${ }^{2}$ Having a realistic meta-theory about economics is different from having a realist meta-theory. It is not clear whether Blaug could be justifiably characterized as consistently espousing philosophical realism even though I believe he wanted to be so characterized.
} 
normative unrealisticness of his prescriptions about how to do better economics, making them unachievable as requirements for scientific practice and its assessment. In my view, normative methodology is just fine, but in order for the normative assessments and prescriptions to be adequate and effective, one needs to develop a deep descriptive understanding of the structure, presuppositions, and preconditions of the practice that is being normatively evaluated and regulated.

While Blaug made many sharp and intuitively agreeable observations about economics and its deficiencies, he neither adopted nor built an elaborate methodological theory that would have justified and organized these observations. There was no (whether stable or progressively evolving) meta-theory, or a coordinated set of such theories grounding his critical observations in a consistent manner. This may sound strange given that he regularly appealed to Popper and Lakatos and their versions of falsificationist methodology. But first, there indeed were two (or more) different versions of falsificationism, and it seemed the versions were often conflated, and were invoked inconsistently. And, second, he used other methodological argumentssuch as those based on the alleged trade-off between rigour and relevance-that were not based on, or even consistent with, falsificationism or perhaps any other systematic meta-theory.

Instead of engaging myself in a thorough and detailed scrutiny of Blaug's methodological writings, I will focus on two of his favourite arguments and give very brief and selective comments. One of the arguments is on falsifiability, the other is on relevance. Blaug claims that economics fails insofar as it lacks these two properties-and that it often does. In both cases, I suggest that the broad underlying intuitions are on the right track, whereas the specific elaborations are flawed.

\section{Falsifiability: when theory and facts conflict at two levels}

Blaug believed that good science first develops theories that are falsifiable (in that they entail predictions that can be in conflict with observable evidence), and then attempts to falsify such theories. He accused economics of failing to be good science in this sense. Economics would become a proper science, or a better science, by revising its practices so as to better abide with falsificationist prescriptions. Here is a passage that summarizes the core ideas:

That economists rarely practice falsificationism only demonstrates the need to preach falsificationism day in and day out, always 
assuming that falsificationism is in fact practicable in economics and that the history of our subject displays some instances of it (Blaug 1992b, 57).

There is a general background intuition here that I find agreeable. It would be good for economists to be more welcoming of-and responsive to-criticism that questions their theoretical and other ideas, whether minor or major, including criticism that appeals to empirical evidence. The balance between dogmatism and responsiveness to criticism should be critically reconsidered.

What invites special attention in the passage quoted above is the relationship between two ideas, namely between the descriptive claim that "economists rarely practice falsificationism" and the normative proposition that there is "the need to preach falsificationism day in and day out". This is a version of the familiar tension or discrepancy between theory and the facts. Any such tension can be resolved in two ways, broadly speaking. Both ways seek to align the theory and the facts by removing the discrepancy. One either revises the theory or modifies the facts (or both-to make the set of options complete). These options are familiar in the case when economic theory is perceived to be in conflict with the evidence (or with the world itself). Blaug would generally choose the former option: to revise the economic theory. This is indeed advised by his falsificationism. Yet in the case of methodological theory, his choice was different: he would rather change the facts of economic inquiry while sticking to the methodological theory. The way to change the facts of research practice is to preach the theory of falsificationism. This latter choice (to change the current style of economic inquiry), Blaug hoped, would force economists to be more inclined to make the former choice (to change economic theory) when economic theory and the facts were in conflict.

A necessary condition for judiciously preaching falsificationism "day in and day out" is, as Blaug puts it, "always assuming that falsificationism is in fact practicable in economics". It must be possible to practice falsificationism for it to make sense to preach it. If it could be substantiated that falsificationism is practicable, the next question would be to ask whether practicing it would be recommendable (and it is possible to argue that it would not). But we do not need to ask the latter question about recommendability if we have answered the previous question about practicability negatively. As we know, the assumption about practicability is questionable-many would say it is a descriptively 
unrealistic assumption. If this is correct, then preaching falsificationism would be normatively unrealistic as it would recommend the pursuit of a utopian goal, a goal that cannot be attained, not even with a tolerable degree of approximation.

There is no need to repeat the investigations and debates of the 1980s and early 1990s here (see, e.g., Hands 1992). Among the conclusions was that falsificationism is impracticable in economics. This can be summarized by referring to the Duhem-Quine challenge and the impossibility of relieving it by an effective epistemic control for the inescapable ceteris-paribus clause involved. One can argue that falsificationism is even less practicable in economics than, say, in experimental physical sciences (adding that it has not been accepted as a philosophy of the latter either). Basing testing on predictionsespecially its ambitious versions-is harder in economics and is further complicated by the anti-predictivist arguments implied by certain fashionable economic theories themselves.

Even if falsificationism as a specific methodology cannot be sustained, I still think it is important to defend something like itsomething that accommodates the important intuitions that Blaug tried to articulate in flawed falsificationist terms. The generic supportable idea is that economic theories and models should be so formulated and used that they can be made accountable to the facts. Forces such as dogmatism, formal elegance or ideological appropriateness should not dominate the acceptance and rejection of economic theories. Blaug himself considered other specific ideas in this spirit. I will discuss one of them next.

\section{Relevance and its alleged trade-off with rigour}

In the later years Blaug talked less about falsifiability and more about "relevance", another property of theories that he considered desirable. This gives another sense in which a theory can be realistic. Blaug believed that there is another quality that is in conflict with it, namely what he calls "rigour".

There is a trade-off in economics (and elsewhere) between rigor and relevance: the more we achieve deductive certainty in our arguments, the less likely it is that we will achieve socially and politically relevant conclusions (Blaug 2009a, 219). 
Again, I find the underlying intuitions here quite agreeable. Economics should provide helpful services to solving the important problems of the humankind, and sometimes this would require (putting it very intuitively indeed) less activity on the blackboard and more in the field (while not denying the essential importance of the role of the blackboard). However, things get much more complicated as soon as we start looking at the details of such statements.

My immediate comment on Blaug's statement is that making bold claims about such a general trade-off requires defining the concepts of 'rigour' and 'relevance', with a little bit of more rigour. Unfortunately, it seems that Blaug may have applied a second-order version of the alleged trade-off: as if he wanted so badly to make relevant methodological claims about economics that the attempted relevance of these claims was traded-off for the rigour of the arguments. Let us see what he says.

Blaug briefly discusses some meanings of 'rigour', but he only deals with the kinds of mathematical rigour that he believes characterizes economic inquiry (Blaug 2009a, 220). This is unfortunately narrow as it ignores other kinds of rigour, such as rigour in the analysis of concepts and data, and rigour in inferences from models to the world. ${ }^{3}$

As for the meanings of 'relevance', Blaug says even less, close to nothing. In order to assess his thesis, we need to do a little more. It is useful to start with a general notion of relevance that makes it explicit that relevance is a relational property. We might say, for example, that some $\mathrm{X}$ is relevant to some $\mathrm{Y}$, which can be taken to mean that $\mathrm{X}$ has or might have some sufficiently significant consequences for $\mathrm{Y}$. Here we may take $X$ to designate a theory or model, or a stream or approach in economics. In principle, $\mathrm{Y}$ can be anything, provided it is perceived as somehow worthwhile as a goal or purpose. Note that this way of conceiving of relevance is normatively neutral in two ways. First, it permits the consequences of $\mathrm{X}$ for some $\mathrm{Y}$ to be either beneficial or harmful. Second, it permits the desirability of $\mathrm{Y}$ to be contestable. I think these are important features for the notion of relevance to be of use when assessing economics. At the same time, the limitations of the concept can be seen more readily.

Blaug's opening statement of the trade-off that was cited above includes a more specific version of relevance, specifying the Y: his definition talks about "socially and politically relevant conclusions"

\footnotetext{
${ }^{3}$ At one point he says that the rigour of game theory is "only epistemic rather than purely mathematical" (Blaug 2009a, 224), but it remains unclear what this means.
} 
suggesting that for him Y consists of social and political purposes. In line with this interpretation, making it a little more specific still, a piece of economic inquiry is irrelevant if it involves a "failure to draw any policy conclusions" (Blaug 2009a, 221).

The same article puts forth other ideas of what relevance and irrelevance are, and it is obvious that these ideas do not boil down to one and the same thing. One of them suggests that purpose $\mathrm{Y}$ is "understanding" the real world: Blaug criticizes Sraffian economics for being "irrelevant to our understanding of the real world" (Blaug 2009a, 221). While this could be taken to be consistent with the generic idea of irrelevance as failure to have "socially and politically relevant conclusions", this is not the same thing as the more specific "failure to draw any policy conclusions".

We can find a further sense of relevance in the same article. In this sense the relevance of game theory is "undeniable since it is concerned with interaction between instrumentally rational individuals and that is almost a definition of the domain of social science" (Blaug 2009a, 224). This is rather striking as it implies, among other things, that any highly imaginary other-worldly (game theoretic or whatever) toy model satisfies the desideratum of relevance insofar as it contains ideas about "interaction between instrumentally rational individuals"-regardless of how fictional these may be.

Yet another notion of relevance is suggested by the claim that a piece of economics is "irrelevant to the major concerns of modern economists" (Blaug 2009a, 221). An appeal to such concerns as a mark of relevance is somewhat curious given Blaug's complaints about the economics profession not being sufficiently concerned with socially and politically relevant issues. If the concerns of contemporary economists are misguided in such a way, then it should seem odd to criticize a stream of economics for being irrelevant to those concerns. Things become even more curious as we next read this:

Relevance is not a matter for individual opinion but a social judgment of the community of professional economists. We assess that judgment by inspecting the professional literature, by citation counts, or by any of the other methods of bibliometrics. [...] it is the nearest approximation we have to a supreme tribunal of social science (Blaug 2009a, 221). 
Blaug then appeals to this tribunal against Sraffian economics. This actually suggests a version of relevance, namely relevance to getting one's work published and widely accepted, or recognized, measured in terms of citations. Now it seems obvious that much of standard economics that Blaug finds dubious is relevant just in this sense. This version of relevance may be used to speak against one target of criticism-here Sraffian economics-but it does so at the price of inconsistency by speaking in favour of other streams in economics that Blaug otherwise finds problematic.

I might add a couple of exploratory remarks on this framework of rigour and relevance in relation to falsificationism. First, there does not seem to be any necessary connection between a theory being falsifiable and that theory being policy relevant, such that being more falsifiable would go together with being more policy relevant. It is conceivable that a policy irrelevant theory is closer to being falsifiable than more ambitious policy relevant theories. Relevance and falsifiability seem independent from one another. Second, one may wonder if there is a connection after all, via rigour, but not what Blaug might have wanted. On the one hand, he thinks deductive reasoning is one of the marks of rigour supposedly in conflict with relevance, but on the other hand, his favourite falsificationism is a deeply deductivist doctrine. Third, saying that "if economics is to be practically relevant, there must be some concrete truths in which we can place confidence" (Blaug 1994, 119) is hard to reconcile with the falsificationist doubt about confidence in truths. Perhaps a resolution to these misgivings comes from the realization that no consistent falsificationism is being endorsed by Blaug: "It is high time that economists re-examined their long-standing antipathy to induction [...]" (Blaug 2002, 50).

I will have a little more to say on the issues of relevance and rigour later, but let me make two further observations now. First focusing on a narrow version of the alleged general trade-off between mathematical rigour and practical relevance-or "policy relevance"-can be easily questioned (or falsified!) by pointing out counterexamples. Such examples include research serving practical goals such as building a skyscraper or sending a spacecraft to Mars. These practices require a great deal of mathematical rigour, so in such cases rigour is not at all in conflict with practical relevance, but is instead required for relevance. If one were to argue that there are major qualitative differences between these cases and economics, some detailed arguments would be needed. 
Regardless of whether such arguments are forthcoming, it seems that economics itself provides representative examples that speak against the alleged trade-off. Being mathematically rigorous should in no way as such be an obstacle to drawing policy conclusions-just think of Robert Lucas and the new classical macroeconomics, or new Keynesian macro for that matter. It is a separate issue that those conclusions are empirically and ideologically contestable.

The second observation breaks away from the above narrow interpretation of rigour in the alleged trade-off. I am myself inclined to agree that mathematical rigour has become overemphasized in economics (a claim that would require a lot of qualifications to be sustained), but I would insist on immediately adding that many other kinds of rigour are underemphasized. It is not advisable to waste a good concept, that of 'rigour', by giving it an all too narrow meaning and confining it to mathematical economics. In broader senses of the term, I think economics needs more rather than less rigour in order to be more relevant to the most important real-world issues.

In conclusion, I do not presently see much reason for believing in a general trade-off between rigour and relevance. If there are no good such reasons, then the very idea should be abandoned.

\section{WIDENING HORIZONS: MODELLING AND INSTITUTIONAL CONSTRAINTS}

I will next suggest that we need to augment our horizons to be in a position to properly assess Blaug's intuitions and arguments, and to see how his worries about economics could be dealt with in a more rigorous and less unrealistic manner. To get rid of an unrealistic methodology that is out of touch with real scientific practice, we need to look at what really happens in economics. And we need to expand our conceptual toolbox needed for understanding the complexities of actual scientific inquiry. I will offer a very brief and selective outline, bringing in just two themes: scientific modelling, and the institutions of inquiry.

\section{Implications of model-based inquiry}

Blaug's methodological campaign might be understood as being built on a hypothetico-deductive image of economic inquiry. Good science is a matter of deriving predictions from hypothetical theories and law-like statements, then comparing the predictions with empirical data, and finally inferring to the acceptability of the theories and law statements. The Popperian version of this requires looking for negative falsifying 
evidence and not accepting theories as anything more than as not-yetfalsified. At no point is inductive inference supposed to be exercised.

This image of science has no prominent role for models. But models do play a prominent role in economic inquiry. Neglecting the issues of modelling and the challenges they pose for methodological scrutiny is one source of unrealisticness in Blaug's methodological statements. Accommodating models and understanding how they function will have important implications for how we should judge economics. Models can serve a variety of different purposes, and for each type of purpose, they are to be assessed differently. So for example, straightforward predictive testing is not the way to go except for models that are built with the goal of prediction in mind (while keeping in mind that 'prediction' itself can mean a number of different kinds of thing).

For some models it does not matter much at all that their "predictions" have little match with the data-just think of my favourite, Johann Heinrich von Thünen's (1966 [1826]) highly idealized model of agricultural land use and its 'prediction' of concentric rings that regularly fail to match with actual land use patterns. These models have been built for other purposes, such as that of a "minimal model" depicting-and it is hoped truthfully depicting-a causal mechanism that contributes to the phenomena to be explained, yet does not influence the phenomena alone but together with other mechanisms and conditions (von Thünen's simplest model isolates a mechanism that contains transportation costs and land values as functions of distance; see Mäki 2011). Or they may be used for exploring possible causal scenarios, in search for plausible how-possibly explanations-such as in the case of Thomas Schelling's (1969) segregation models. These models are imagined systems that isolate a limited set of causal factors and that are described in terms of apparently false idealizing assumptions. It would be inappropriate to try to test either kinds of model simply by their assumptions or predictive implications so as to result in a possible falsification.

Models are artificially constructed objects that are examined in place of real systems in the wild. The tricky issue-the ultimate methodological issue in economics-is about how these two systems are related to one another. It is useful to draw a distinction between the study of the properties of models on the one hand, and the study of how these models are related to the real world and perhaps policy concerns, on the other. It is tempting to suggest that the examination 
of models is a rigorous activity, while relevance is a separate issue that would be checked by examining how models relate to real-world concerns. But this would be too simplistic (given what we have said about the notions of rigour and relevance above). The study of models can be directly relevant to a variety of purposes (such as isolating real effective causal mechanisms and conceiving real possibilities and impossibilities), while one may also want to study how models relate to real world concerns to be more rigorously conducted than it often tends to be.

Consider a representative example. Many theoretical models in economics provide an account of how things might possibly go in the world, without yet implying or involving any claims about how they actually go. Economists examine these models without systematically linking them with empirical data. One might suspect that such howpossibly models have no relevance to policy concerns, but this would be too hasty. Even how-possibly models can be policy relevant. Again Schelling's (1969) segregation models are a case in point (see Sugden 2002; Aydınonat 2008; Grüne-Yanoff 2009; Mäki 2009). They can be examined on a blackboard, on a checkerboard, in a computer simulation, without empirical research on actual cases of segregation. The racial versions of these models undermine the commonsense belief that racial segregation in urban housing markets necessarily results from discriminatory racial attitudes among individuals by pointing out that it is possible for segregation to arise without such attitudes. This discovery has consequences for the array of policy strategies that should be considered, so the models are clearly policy relevant. Naturally, choosing the right policy instruments in each particular case requires empirical enquiry about the detailed actualities of those cases, but this is not the only realm of policy relevance. Nor should the focused examination of models be the only realm of rigour.

So how should one articulate Blaug's valuable intuitions while acknowledging the importance of modelling in economics? The distinction between surrogate modelling and substitute modelling might be helpful (Mäki 2009). Surrogate models are objects that are directly examined in order to indirectly learn about their targets in the real world, while substitute models are examined for their own sake, with no such further goal in place. Substitute models are the easy playgrounds that substitute for possible hard-to-access real-world targets, while surrogate models serve as tools for the hard task of 
preparing epistemic access to such targets. In both cases the study of models without immediate and full attention to how they link to real targets is an entirely legitimate activity, but only in the case of surrogate modelling would the research community in due time take further steps in establishing those links. Naturally, given such a characterization, the distinction between these two sorts of modelling cannot be sharp, and contestable boundary cases cannot be avoided-but this as such does not distort the messy complexities of scientific inquiry (while all too neat meta-theoretical concepts might).

It remains to be seen whether these concepts, together with some heuristics, perform better than does Blaug's failed dichotomy between rigour and relevance. Performing better here amounts to being descriptively more adequate and normatively more feasible. Surrogate modelling would be a matter of exercising rigour both in examining the properties of models and in examining how they connect with some real world targets, and the latter connection would help guarantee relevance to real world concerns (that would not in all cases involve direct policy relevance). Substitute modelling would at most involve rigour in the study of models, and would lack real world relevance.

\section{Preaching and institutional design}

Another extension we need in our horizons deals with the institutions of economic inquiry. Otherwise we will not fully understand the actual practices and conventions of economic inquiry, nor will our normative assessments and prescriptions have much force, and thus our methodology will remain unrealistic, both descriptively and normatively. Nothing in science happens in an institutional vacuum, whether testing or modelling, or judgements of rigour and relevance, and institutions often make a difference. Furthermore, the institutions of inquiry are neither historically constant nor completely uniform across scientific disciplines. Without due attention to these institutions, any preaching will fall on deaf ears.

It is also possible that without a systematic understanding of the institutional dynamics of scientific research one may unintendedly promote trends that one would otherwise find unfortunate. Consider Blaug's campaign for more practically relevant economics in relation to the new actually emerging regime of societal accountability in science 
("Mode 2" and all that). ${ }^{4}$ Might his campaign be used for supporting the current trend toward reducing the autonomy of academic science and bringing it into closer contact with the practical demands deriving from politics and business?

In its falsificationist mode, Blaug's normative methodology comes in three waves. The first-order falsificationist rule asks economists to make their theories falsifiable, and to try to falsify them with negative evidence. Second, in response to failures to do so, Blaug puts forth the second-order fortifier addressed to economists: "try harder!" The third wave is the instruction addressed to methodologists, asking them "to preach falsificationism day in and day out".

Now if falsificationism is impracticable, waves two and three cannot have the consequences the preacher intends. Preaching makes sense and may become effective when the endorsed rule or principle is practicable, but, especially if it is difficult to practice, mere preaching may be inadequate. Institutional facilitators are needed too. Indeed, much depends on what economists would call the incentive structure embedded in the industrial organization of inquiry.

As a perceptive observer, Blaug naturally had an eye for these facts. He refers to "a well-established professional culture that values technical facility above all else" (Blaug 2002, 44) and "a veritable professional treadmill with a built-in momentum that feeds continually on the pressure to publish in prestigious journals in order to gain employment in prestigious institutions" $(2002,45)$. Yet in response to his own question, "What to do?" (2002, 44), he focuses on individual economists' behaviour in potentially breaking away from "the dominant fashion for economics papers" $(2002,45)$. It would be too much to ask younger scholars to risk their careers, so the hope must be laid on "the older members of the profession to show the way with empirically relevant research grounded in the attempt to confront outstanding policy issues" $(2005,45)$. If the desired change indeed depends on the initiative of individual economists, then the proper task for methodologists is to preach, and to preach for a change in individual behaviour.

Some gentle preaching addressing individuals is often just fine, but without ideas for a re-design of the institutions of economics, preaching may become just a matter of ineffectively scratching the surface without

\footnotetext{
${ }^{4}$ On "Mode 2" of knowledge production in the sociology of science, see, for example, Nowotny, et al. 2001.
} 
lasting effect. A more realistic campaign should go deeper and develop a plan for a structural change in the relevant institutions. It would be more realistic both in the descriptive sense of providing an adequate account of the cognitive and institutional preconditions of economic inquiry and in the normative sense of providing possibly effective recipes for reform. This requires a rich framework of concepts beyond those of testing and prediction, rigour and relevance, and the like. Economics itself, as a subject dealing with optimal social organization, may contribute to this framework.

\section{CONCLUDING REMARK}

As I mentioned in the introduction, my reason for not citing Mark's work frequently was that I did not see an elaborate and progressive methodological theory that I could accept or consider as having a promising future. In the 1980s, I was among the few (together with others like Dan Hausman, Bert Hamminga, and Alex Rosenberg) who did not adhere to the Popperian and/or Lakatosian framework and agenda in relation to the methodology and philosophy of economics (see, e.g., Rosenberg 1986; Hausman 1988; Mäki 1990, 2008; and on the rise and fall of this framework, see Backhouse 2012). ${ }^{5}$

I thought the most important issues regarding the connections of economics with the real world were much more complicated than can be resolved or even envisaged from within the Popperian and Lakatosian frameworks. In the course of the 1980s, I had developed elements for a different account that I believed would be more adequate for addressing these issues. These included notions such as 'isolation' and 'idealization', and the account kept evolving so as to become an account of modelling. In this project, I learned a great deal by examining 19th-century economists' writings. These included J. H. von Thünen's Isolated State (1966 [1826]), whose highly "unrealistic" land-use model I interpreted as an intendedly true account of a simple mechanism that is isolated by employing false idealizing assumptions.

Mark happened to be an expert on von Thünen. It must have been already in the early years of the 2000s when he once attended a seminar at which I summarized my reading of von Thünen. Mark's reaction was

\footnotetext{
${ }^{5}$ Note that there is a difference between sharing a more or less Popperian/Lakatosian framework and agenda on the one hand, and accepting Popperian/Lakatosian principles and prescriptions of good science, on the other. In the course of the 1980s and 1990s, methodologists and historians of economics gave up the latter more easily than the former; see Mäki 1990.
} 
somewhat dramatic, the verbal side of it put more or less in these words: "Oh what a fool I am! How come that never occurred to me!" I thought that was a truly Popperian reaction (Popperian-the-doctrine rather than Popperian-the-man), even though it was understandable that within the Popperian framework, the chances of reaching the insight were not so good simply because the required conceptual resourcesthose of idealization and isolation-were not given the prominent role they deserve.

On some other topics too, Mark was quite responsive to challenging evidence and arguments, and was prepared to revise his views accordingly. These included his understanding of Milton Friedman's 1953 essay on which he moved away from Popperian and straightforward instrumentalist interpretations (Blaug 2009b). In these situations he acted like a good meta-methodological or second-order Popperian (in some generalized broad sense). Had he lived longer, he would probably have revised his first-order Popperianism (in a more narrow sense) and the argument from rigour and relevance more than he actually did. And we would have had a chance to learn from him even more than we actually did.

\section{REFERENCES}

Aydinonat, N. Emrah. 2008. The invisible hand in economics: how economists explain unintended social consequences. London: Routledge.

Backhouse, Roger E. 2012. The rise and fall of Popper and Lakatos in economics. In Philosophy of economics, ed. Uskali Mäki; vol. 13 of Handbook of the philosophy of science, eds. D. Gabbay, P. Thagard, and J. Woods. Amsterdam: Elsevier, 25-48.

Blaug, Mark. 1978 [1962]. Economic theory in retrospect [third edition]. Cambridge (UK): Cambridge University Press.

Blaug, Mark. 1980. The methodology of economics, or how economists explain. Cambridge (UK): Cambridge University Press.

Blaug, Mark. 1992 [1980]. The methodology of economics, or how economists explain [second edition]. Cambridge (UK): Cambridge University Press.

Blaug, Mark. 1992b. Commentary [on D. Wade Hands]. In Post-Popperian methodology of economics: recovering practice, ed. Neil De Marchi. Boston: Kluwer, 55-59.

Blaug, Mark. 1994. Why I am not a constructivist: confessions of an unrepentant Popperian. In New directions in economic methodology, ed. Roger Backhouse. London: Routledge, 109-136.

Blaug, Mark. 1997. Ugly currents in modern economics. Policy Options, 17 (7): 3-8.

Blaug, Mark. 2002. Ugly currents in modern economics. In Fact and fiction in economics: models, realism, and social construction, ed. Uskali Mäki. Cambridge: Cambridge University Press, 35-56.

Blaug, Mark. 2009a. The trade-off between rigour and relevance: Sraffian economics as a case in point. History of Political Economy, 41 (2): 219-247. 
Blaug, Mark. 2009b. The debate over F53 after fifty years. In The methodology of positive economics: reflections on the Milton Friedman legacy, ed. Uskali Mäki. Cambridge (UK): Cambridge University Press, 349-354.

Grüne-Yanoff, Till. 2009. Learning from minimal economic models. Erkenntnis, 70 (1): 81-99.

Hands, D. Wade. 1992. Falsification, situational analysis, and scientific research programs: the Popperian tradition in economic methodology. In Post-Popperian methodology of economics: recovering practice, ed. Neil De Marchi. Boston: Kluwer, 19-53.

Hausman, Daniel M. An appraisal of Popperian economic methodology. In The Popperian legacy in economics, ed. Neil De Marchi. Cambridge: Cambridge University Press, 65-86.

Mäki, Uskali. 1990. Methodology of economics: complaints and guidelines. Finnish Economic Papers, 3 (1): 77-84.

Mäki, Uskali. 2008. Method and appraisal in economics: 1976-2006. Journal of Economic Methodology, 15 (4): 409-423.

Mäki, Uskali. 2009. MISSing the world: models as isolations and credible surrogate systems. Erkenntnis, 70 (1): 29-43.

Mäki, Uskali. 2011. Models and the locus of their truth. Synthese, 180 (1): 47-63.

Nowotny, Helga, Peter Scott, and Michael Gibbons. 2001. Re-thinking science: knowledge and the public in an age of uncertainty. Cambridge (UK): Blackwell.

Rosenberg, Alexander. 1986. Lakatosian consolations for economics. Economics and Philosophy, 2 (1): 127-139.

Schelling, Thomas C. 1969. Models of segregation. American Economic Review, 59 (2): 488-493.

Sugden, Robert. 2002. Credible worlds: the status of theoretical models in economics. In Fact and fiction in economics: models, realism, and social construction, ed. Uskali Mäki. Cambridge: Cambridge University Press, 107-136.

von Thünen, Johann Heinrich. 1966 [1826]. Isolated State, tr. Carla M. Wartenberg, ed. Peter Hall. Oxford/New York: Pergamon Press.

Uskali Mäki is academy professor at the Academy of Finland, professor of practical philosophy at University of Helsinki, and director of the Centre of Excellence in the Philosophy of the Social Sciences (TINT), based at the Department of Political and Economic Studies, University of Helsinki. He is former academic director of the Erasmus Institute for Philosophy and Economics (EIPE), former editor of the Journal of Economic Methodology (JEM), and former chair of the International Network for Economic Method (INEM). His research interests include models and idealizations, local scientific realism, interdisciplinarity, and scientific imperialism.

Contact e-mail: <uskali.maki@helsinki.fi>

Website: <http://www.helsinki.fi/tint/maki/> 